\title{
Surface Enamel Remineralization: Biomimetic Apatite Nanocrystals and Fluoride Ions Different Effects
}

\author{
Norberto Roveri, ${ }^{1}$ Elisa Battistella, ${ }^{2}$ Claudia Letizia Bianchi, ${ }^{3}$ Ismaela Foltran,, ${ }^{1}$ \\ Elisabetta Foresti, ${ }^{1}$ Michele Iafisco, ${ }^{1,2}$ Marco Lelli, ${ }^{1}$ Alberto Naldoni, ${ }^{3}$ \\ Barbara Palazzo, ${ }^{1,2}$ and Lia Rimondini ${ }^{2}$ \\ ${ }^{1}$ Department of Chemistry "G. Ciamician”, University of Bologna, Via Selmi 2, 40126 Bologna, Italy \\ ${ }^{2}$ Department of Medical Sciences, University of Eastern Piedmont "Amedeo Avogadro", Via Solaroli 17, 28100 Novara, Italy \\ ${ }^{3}$ Department of Physical Chemistry and Electrochemistry, University of Milano, Via Golgi 19, 20133 Milano, Italy
}

Correspondence should be addressed to Norberto Roveri, norberto.roveri@unibo.it

Received 13 October 2008; Accepted 22 January 2009

Recommended by Alan K. T. Lau

A new method for altered enamel surface remineralization has been proposed . To this aim carbonate-hydroxyapatite nanocrystals which mimic for composition, structure, nanodimensions, and morphology dentine apatite crystals and resemble closely natural apatite chemical-physical properties have been used The results underline the differences induced by the use of fluoride ions and hydroxyapatite nanocrystals in contrasting the mechanical abrasions and acid attacks to which tooth enamel is exposed. Fluoride ions generate a surface modification of the natural enamel apatite crystals increasing their crystallinity degree and relative mechanical and acid resistance. On the other hand, the remineralization produced by carbonate-hydroxyapatite consists in a deposition of a new apatitic mineral into the eroded enamel surface scratches. A new biomimetic mineral coating, which progressively fills and shadows surface scratches, covers and safeguards the enamel structure by contrasting the acid and bacteria attacks.

Copyright (c) 2009 Norberto Roveri et al. This is an open access article distributed under the Creative Commons Attribution License, which permits unrestricted use, distribution, and reproduction in any medium, provided the original work is properly cited.

\section{Introduction}

Dental erosion is the chemical wear of the dental hard tissue without the involvement of bacteria [1]. Its clinical relevance is becoming wider and wider [2-6], and it is considered one of the main tooth pathologies able to cause patient discomfort, after periodontal diseases and caries.

Its aetiology is related to the enormous increase in consumption of soft drinks, fruit juices and sport drinks consumption [7]. However, other acid sources such as drugs containing syrups, analgesics and vitamin $\mathrm{C}$ intake and environmental acid exposure in working conditions are claimed to be related to enamel erosion [8-12].

The mechanisms involved in the damage of dental hard tissue are the acid attacks on the outer few micrometers of the enamel, which brings to demineralization and dissolution of the mineral phase [13-16].
Hydroxyapatite is the main constituent of the dental tissues representing in enamel and dentine the $95 \mathrm{wt} \%$ and $75 \mathrm{wt} \%$, respectively.

The primary determinant of dissolution rate is the solubility of hydroxyapatite (HA) which is related to $\mathrm{pH}$, and the presence of salivary pellicle also appears to be important [17-19].

Frequent application of a high concentration of topical fluoride may be of some benefit in preventing further demineralization and increasing the abrasion resistance of erosion lesions [20].

In vitro studies have shown that synthetic carbonatedhydroxyapatite (CHA) dissolution inhibition is a logarithmic function of the fluoride concentration in solution [21].

Systemic intake of fluoride during tooth formation has been claimed to be effective in caries prevention just by means of the apatite demineralization inhibition. According 
to recommended daily allowances (RDAs) panel of the European Food Safety Authority, an intake of $0.1 \mathrm{mg}$ fluoride $/ \mathrm{Kg}$ body weight/day in children up to the age of eight years can be considered as the dose below which there will be no significant occurrence of moderate forms of fluorosis in permanent teeth [22].

However, it is important to consider that fluoridated water, fluoride supplements in diet, fluoride toothpaste, and topical fluoride applications have been identified as sources of enamel fluorosis [23]. Moreover, the "probably toxic dose" of fluoride-the dose which should trigger therapeutic intervention and hospitalization-is $5 \mathrm{mg} / \mathrm{Kg}$ of body weight, but as currently packaged, many dental products contain sufficient fluoride to exceed the "probably toxic dose" for young children [24].

Most of the products and devices used to contrast enamel and dentine erosion, such as fluoride [25-28], behave by reducing apatite dissolution rather than aiming to promote mineralization through apatite crystallization or replacement of the lost mineral. Hydroxyapatite, as well as in bone, is responsible for the mechanical behavior of the dental tissues. Unlike bone, in enamel and dentine, when HA is dissolved or abraded, it cannot spontaneously remineralize because enamel contains no cells and dentine apposition occurs only toward the pulp tissues. Therefore, both enamel and dentine can be reconstructed only by the application of alloplastic materials providing a sort of prosthetic restoration. In view of this situation, the demineralized area and micrometric sized scratches, which normally occur on enamel surface as a consequence of microwear and acid attack [29], cannot be repaired biologically nor prosthetically.

Hydroxyapatite has been widely subjected to experiment as bone filler and prosthetic coating due to its biocompatibility and osteoconductivity, representing an elective material covering a wide range of applications for bone substitution and interface [30]. Poorly crystalline HA nanocrystals, in addition to the excellent biological properties of HA, such as nontoxicity and lack of inflammatory and immunitary responses, have bioresorption properties under physiological conditions. This property can be modulated by modifying its degree of crystallinity, which is achieved by implementation of innovative synthesis with a nanosize crystals control. In the last decade, advanced technology has been utilized to synthesize a new generation of biomimetic apatitic alloplastic materials which can optimize the interaction with biological entities thanks to their strong surface bioactivity [31]. The aim of the present study is to highlight the effect of the synthetic biomimetic hydroxyapatite crystals respect the fluoride ions into the remineralization in vitro of human enamel surface.

\section{Materials and Methods}

2.1. Chemicals. All the chemicals reagents used were of high chemical grade from Sigma-Aldrich, Mo, USA.

2.2. Synthesis of Carbonate-Hydroxyapatite Nanocrystals. Plate-acicular shaped carbonate-hydroxyapatite nanocrystals about $100 \mathrm{~nm}$ in size were synthesized according to a modification of the method previously reported [32] and patented [33]. CHA nanocrystals about $100 \mathrm{~nm}$ in size were precipitated from an aqueous suspension of $\mathrm{Ca}(\mathrm{OH})_{2}$ $(0.17 \mathrm{M})$ by slow addition of $\mathrm{H}_{3} \mathrm{PO}_{4}(0.15 \mathrm{M})$. The reaction mixture was stirred at $37^{\circ} \mathrm{C}$ for 12 hours, and then stirring was suspended allowing the deposition of CHA nanocrystals. Synthesized CHA $100 \mathrm{~nm}$ sized nanocrystals were isolated by filtration of the mother liquor, repeatedly washed with water and freeze-dried. The fraction of plate-acicular shaped crystals about $100 \mathrm{~nm}$ in size with a granular dimensions ranging from 100 to $150 \mu \mathrm{m}$ was selected for the study. Aliquot of plate-acicular shaped crystals about $100 \mathrm{~nm}$ in size has been allowed, after synthesis to intergrowth in the reaction mixture up to the formation of clusters having dimension ranging from about 0.5 to $3.0 \mu \mathrm{m}$. The cluster aggregation process has been stopped by adding a surfactant (Protelan MST35 $8 \mathrm{wt} \%$ ) in the mother solution.

Plate-shaped carbonate-hydroxyapatite nanocrystals about $20 \mathrm{~nm}$ sized were synthesized according to the method of Liou et al. [34] with some modifications. The nanocrystals were precipitated from an aqueous solution of $\left(\mathrm{NH}_{4}\right)_{3} \mathrm{PO}_{4}(5.1 \mathrm{mM})$ by slow addition of an aqueous solution of $\mathrm{Ca}\left(\mathrm{CH}_{3} \mathrm{COO}\right)_{2}(8.5 \mathrm{mM})$ keeping the $\mathrm{pH}$ at a constant value of 10 by addition of a $\mathrm{NH}_{4} \mathrm{OH}$ solution. The reaction mixture was kept under stirring at room temperature for 24 hours, and then stirring was suspended allowing the deposition CHA nanocrystals. Synthesized CHA nanocrystals were isolated by filtration of the solution, repeatedly washed with water, and freeze-dried. The fraction of plate shaped crystals about $20 \mathrm{~nm}$ in size having granular dimensions ranging from 100 to $150 \mu \mathrm{m}$ was selected for the study.

2.3. Morphological Characterization. Transmission electron microscopy (TEM) investigations were carried out using a Philips CM 100 instrument. The powdered samples were ultrasonically dispersed in ultrapure water, and then a few droplets of the slurry deposited on holey-carbon foils supported on conventional copper microgrids.

Scanning electron microscopy (SEM) observation was carried out by an SEM (Zeiss EVO, 40 XVP) using secondary electrons at $25 \mathrm{kV}$ and various magnifications.

2.4. Structural Characterization. X-ray diffraction powder and enamel surface patterns were collected using an Analytical X'Pert Pro equipped with X'Celerator detector powder diffractometer using $\mathrm{Cu} \mathrm{K} \alpha$ radiation generated at $40 \mathrm{kV}$ and $40 \mathrm{~mA}$. The instrument was configured with a $1^{\circ}$ divergence and $0.2 \mathrm{~mm}$ receiving slits. The samples were prepared using the front loading of standard aluminium sample holders which are $1 \mathrm{~mm}$ deep, $20 \mathrm{~mm}$ high , and $15 \mathrm{~mm}$ wide. The degree of HA crystallinity was evaluated according to the formula [35]

$$
\text { crystallinity }=\left(\frac{X}{Y}\right) 100,
$$

where $X=$ net area of diffracted peaks, and $Y=$ net area of diffracted peaks + background area. 
Crystal domain size along the $\mathrm{c}$ direction was calculated applying Scherrer's formula

$$
L_{(002)}=\frac{0.94 \lambda}{\left[\cos \theta\left(\sqrt{\Delta r^{2}-\Delta_{0}^{2}}\right)\right]},
$$

where $\theta$ is the diffraction angle for plane (002), $\Delta r$ and $\Delta_{0}$ are the widths in radians of reflection (002) at half height for the synthesized and the reference HA materials, respectively, and $\lambda=1.5405 \AA$.

2.5. Infrared Microscopy Spectral Analysis. ATR-IR spectra were recorded on a Thermo Nicolet 380 FT-IR spectrometer equipped with a commercial ATR accessory.

The infrared spectra were registered from 4000 to $400 \mathrm{~cm}^{-1}$ at $2 \mathrm{~cm}^{-1}$ resolution using a Bruker IFS 66v/S spectrometer using $\mathrm{KBr}$ pellets.

ATR spectra were recorded with the cell empty to be used as a blank for subsequent experiments. Samples were made by placing the powder sample onto the Ge ATR crystal. Spectra were collected by averaging 32 scans at $4 \mathrm{~cm}^{-1}$ resolution.

2.6. Specific Surface Area Determination. Measurements were undertaken using a Carlo Erba Sorpty 1750 instrument by measuring $\mathrm{N}_{2}$ absorption at $77 \mathrm{~K}$ and adopting the wellknown BET procedure [36].

2.7. Spectrophotometric Analysis. Phosphorus contents were determined spectrophotometrically as molybdovanadophosphoric acid using $1 \mathrm{~cm}$ quartz cell [37].

Calcium contents were measured using inductively coupled plasma (ICP) optical emission spectrometry (OES) using a Perkin Elmer Optima 4200 DV.

2.8. X-Ray Photoemission Spectroscopy (XPS). Analyses were performed in an M-Probe Instrument (SSI) equipped with a monochromatic $\mathrm{Al} \mathrm{K} \alpha$ source $(1486.6 \mathrm{eV})$ with a spot size of $200 \times 750 \mu \mathrm{m}$ and pass energy of $25 \mathrm{eV}$, providing a resolution for $0.74 \mathrm{eV}$. With a monochromatic source, an electron flood gun was used to compensate the build up of positive charge on the insulator samples during the analyses. $10 \mathrm{eV}$ electrons were selected to perform measurements on these samples. The accuracy of the reported binding energies (BEs) was estimated to be $\pm 0.2 \mathrm{eV}$. The quantitative data were also accurately checked and reproduced several times (at least ten times for each sample), and the percentage error was estimated to be $\pm 1 \%$.

2.9. Statistics Analysis. Determination of HA crystallite domain size along the $c$ direction, bulk and surface $\mathrm{Ca} / \mathrm{P}$ ratio, and specific surface area were carried out 5 times on the same synthesis product. Data are presented as mean value \pm SD. Differences were considered statistically significant at a significance level of $90 \%$.

2.10. In Vitro Enamel Remineralization Procedures. Slabs of enamel $(3 \times 3 \mathrm{~mm})$ were obtained from interproximal surfaces of premolars extracted for orthodontic reasons. After the extraction, the teeth were cut with diamond disks, and the obtained slabs were sonicated for 10 minutes in $50 \%$ ethanol in order to remove any debris. Then, the specimens were etched with $37 \%$ phosphoric acid for 1 minute. Etched slabs were washed in distilled water for 10 minutes under stirring and then air dried. Two different in vitro remineralization procedures have been performed.

The first in vitro remineralization procedure utilizes a $10 \mathrm{wt} \% \mathrm{CHA}$ in the range from 100 to $150 \mu \mathrm{m}$ granules slurries constituted of both $20 \mathrm{~nm}$ or $100 \mathrm{~nm}$ sized nanocrystals. CHA nanocrystals aqueous slurries were applied for 10 minutes on the surfaces of the enamel slabs at room temperature with $100 \%$ relative humidity and then removed by water washing and air dried.

The second in vitro remineralization process utilizes toothpaste containing both fluoride ions and CHA 0.5$3.0 \mu \mathrm{m}$ sized clusters constituted by intergrowth of $100 \mathrm{~nm}$ sized nanocrystals.

Comparable etched enamel slabs were divided into 3groups of treatment using, respectively, fluoride or CHAbased toothpaste and only water (control). Each slab was brushed three times a day for a period of 15 days. The intervals between brushing sessions were at least 5 hours. Every brushing session has been performed for 30 secons by an electric toothbrush using constant pressure and a bean sized toothpaste aliquot wetted with tap water, closely resembling the in vivo usual tooth brushing procedure. After every treatment, the single enamel slab was washed with tap water using a cleaned toothbrush in order to remove residual toothpaste.

\section{Results}

3.1. Synthesis and Characterization of Biomimetic CarbonateHydroxyapatite Nanocrystals. Biomimetic carbonatehydroxyapatite nanocrystals have been synthesized with a nearly stoichiometric in bulk $\mathrm{Ca} / \mathrm{P}$ molar ratio of about 1.61.7 and containing $4 \pm 1 \mathrm{wt} \%$ of carbonate ions replacing prevalently phosphate groups. CHA nanocrystals have been synthesized both about $100 \mathrm{~nm}$ and $20 \mathrm{~nm}$ sized with an acicular and plate morphology, respectively. TEM images of synthetic $20 \mathrm{~nm}$ sized CHA nanocrystals showing the plate-shaped morphology and synthetic $100 \mathrm{~nm}$ sized CHA nanocrystals showing the acicular morphology are reported in Figures 1(a) and 1(b), respectively.

CHA nanocrystals can aggregate in microsized crystal clusters, whose dimensions increase prolonging maturation time in mother solution at constant temperature and stirring [33].

Powder X-ray diffraction patterns of plate shaped about $20 \mathrm{~nm}$ sized CHA nanocrystals and acicular shaped about $100 \mathrm{~nm}$ sized CHA nanocrystals (see Figures 2(b) and 2(c), resp.) show characteristic diffraction maxima of an apatite single phase (JCPDS 01-074-0565).

These X-ray diffraction patterns are compared with those collected for natural carbonate hydroxyapatite from deproteined dentine and enamel reported in Figures 2(a) 


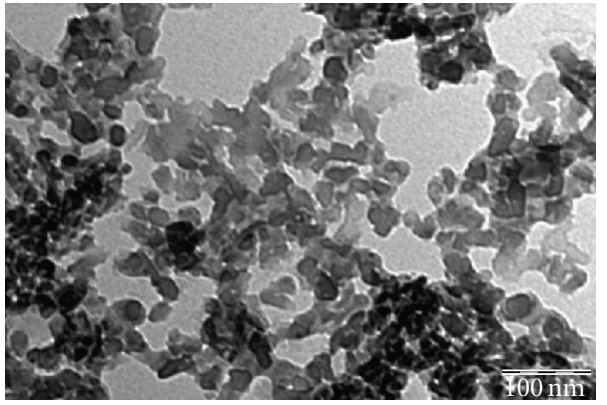

(a)

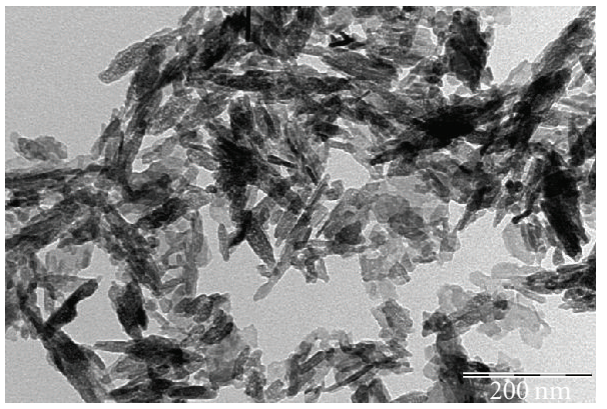

(b)

Figure 1: TEM images of (a) synthetic plate-shaped $20 \mathrm{~nm}$ sized CHA nanocrystals (scale bar $=100 \mathrm{~nm}$ ), (b) synthetic plate-acicular $100 \mathrm{~nm}$ sized CHA nanocrystals (scale bars $=200 \mathrm{~nm}$ ).

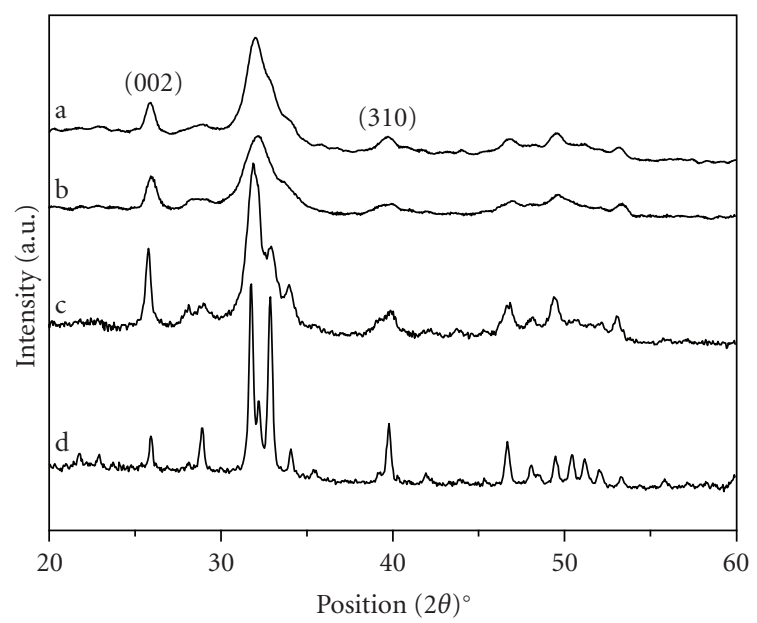

FIGURE 2: X-ray diffraction patterns of (a) natural carbonatehydroxyapatite from deproteined dentine, (b) synthetic plate shaped $20 \mathrm{~nm}$ sized CHA nanocrystals, (c) synthetic plate-acicular shaped $100 \mathrm{~nm}$ sized CHA nanocrystals, and (d) natural carbonatehydroxyapatite from enamel.

and 2(d), respectively. The broadening of the diffraction maxima present in the X-ray diffraction patterns reported in Figures 2(a), 2(b), and 2(c) indicates a relatively low degree of crystallinity, which was quantified according to previous [35]. The degree of crystallinity of synthesized about $20 \mathrm{~nm}$ sized CHA nanocrystals with plate morphology and synthesized about $100 \mathrm{~nm}$ sized CHA nanocrystals with acicular

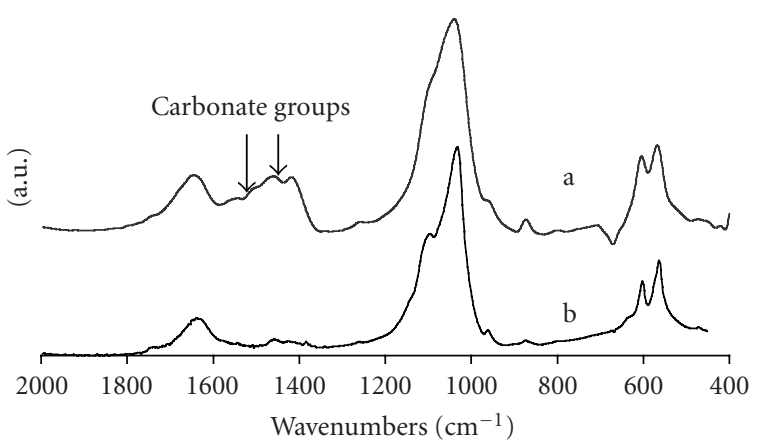

FIGURE 3: (a) FTIR spectra of synthetic $20 \mathrm{~nm}$ sized CHA nanocrystals, (b) natural carbonate-hydroxyapatite from deproteined dentine.

morphology is $30 \%$ and $50 \%$, respectively. The crystallinity degree of about $20 \mathrm{~nm}$ sized CHA nanocrystals is very close to that one determined from the X-ray diffraction pattern of deproteined dentine natural carbonate-hydroxyapatite (28\%) reported in Figure 2(a). Furthermore, the crystallinity degree of natural hydroxyapatite of deproteined enamel, reported in Figure 2(d), is 70\%. The crystal domain sizes along the $\mathrm{c}$ direction have been calculated by Scherrer's formula using the $2 \theta=26^{\circ}$ (002) diffraction peak of the X-ray diffraction patterns reported in Figures 2(a), 2(b), and 2(c). The calculated crystal domain sizes for $20 \mathrm{~nm}$ sized CHA nanocrystals and deproteined dentine are $250 \AA$ and $213 \AA$, respectively. These results obtained by Xray diffraction investigation reveal that the crystal structures of the synthesized CHA nanocrystals are very close to that observed for natural dentine.

The same similarity can be observed from the comparison of the FTIR spectra of synthesized CHA nanocrystals and natural apatite of deproteined dentine reported in Figures 3 (a) and 3(b), respectively. In these spectra, the characteristic absorption bands of phosphate and carbonate groups are clearly resolved. The absorption band at $1468 \mathrm{~cm}^{-1}$ is related to the carbonate group substitution to the phosphate one, while the shoulder at $1545 \mathrm{~cm}^{-1}$ can be considered the contribution of the carbonate group substituting the hydroxyl group in the apatite structure. This finding reveals that synthesized CHA nanocrystals not only contain a similar carbonate amount, but also underline that the carbonate substitution to the phosphate and/or hydroxyl group is very similar in the synthetic and biological crystals.

A surface characterization of the synthetic carbonatehydroxyapatite nanocrystals has been carried out in order to highlight their surface chemical-physical characteristic which directly interfaces and reacts with exposed dental tissues. The ATR spectra (data not shown) of the synthetic about $20 \mathrm{~nm}$ and $100 \mathrm{~nm}$ sized CHA nanocrystals reveal a $4 \%$ and $3 \mathrm{wt} \%$ surface carbonate, respectively. The consistent amount of surface of carbonate percentage present in synthetic CHA is appreciably higher than the surface carbonate percentage present in enamel and dentine about $2 \mathrm{wt} \%$.

Specific surface area of $100 \mathrm{~m}^{2} \mathrm{~g}^{-1}$ and $80 \mathrm{~m}^{2} \mathrm{~g}^{-1}$ has been determined for $20 \mathrm{~nm}$ sized CHA nanocrystals with plate 


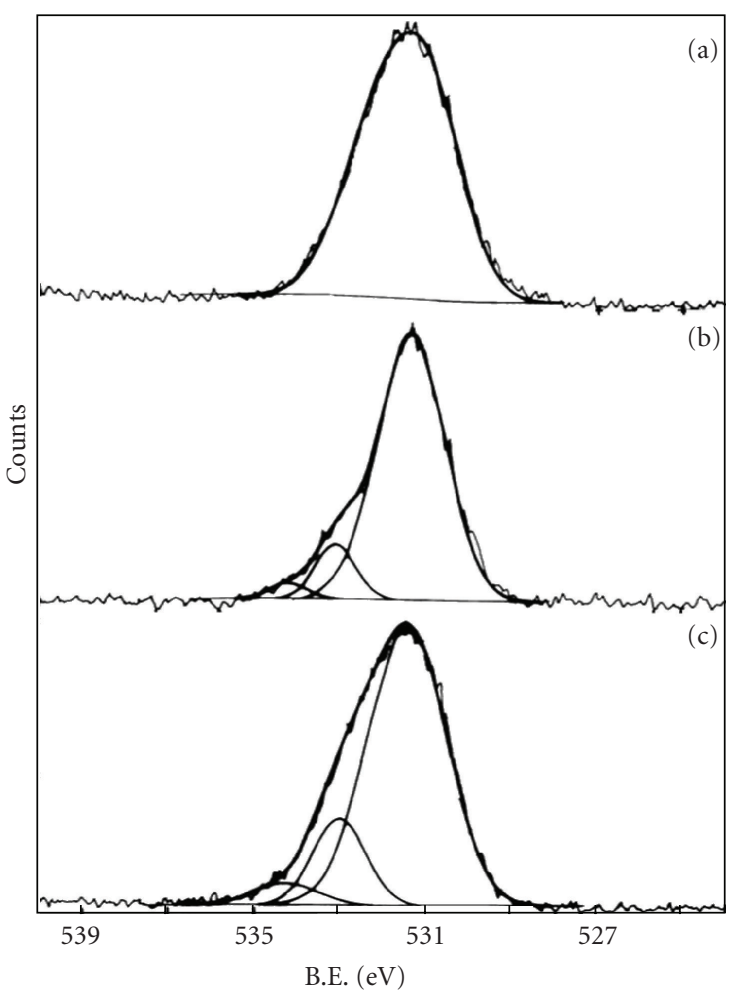

FIgURE 4: XPS analysis of spectral features of (a) the $\mathrm{O} 1 \mathrm{~s}$ region of the enamel demineralized by ortophosphoric acid $37 \%$ for 1 minute, (b) enamel remineralizated by a treatment with synthetic microclusters of CHA nanocrystals $100 \mathrm{~nm}$ sized for 10 minutes, and (c) synthetic microclusters of CHA nanocrystals $100 \mathrm{~nm}$ sized.

morphology and synthesized $100 \mathrm{~nm}$ sized CHA nanocrystals with acicular morphology, respectively. These specific surface area values obtained for synthetic nanocrystals are only slightly lower than the $110 \mathrm{~m}^{2} \mathrm{~g}^{-1}$ obtained for biological nanocrystals.

The surface $\mathrm{Ca} / \mathrm{P}$ molar ratio determined by XPS analysis for CHA nanocrystals and CHA crystals microclusters does not reveal appreciably differences and result significantly lower than $\mathrm{Ca} / \mathrm{P}$ molar ratio determined by ICP analysis in bulk indicating a surface calcium deficiency probably due to surface disorder. In fact, the $\mathrm{Ca} / \mathrm{P}$ molar ratios of 1.7 determined in bulk for synthetic CHA nanocrystals reduce to a value of 1.4-1.5 when determined on the crystals surface by XPS analysis (see Table 1). XPS analysis of spectral features of the $\mathrm{O} 1 \mathrm{~s}$ region of the synthetic $100 \mathrm{~nm}$ sized CHA nanocrystals (see Figure 4(c)) shows a definite O 1s shape fitted by three components: a first, very intense, peak at lower $\mathrm{BE}$ attributed to oxygen in phosphate group, a second peak due to $\mathrm{OH}$ of the carbonate-hydroxyapatite, and a final peak at very high $\mathrm{BE}$, which can be attributed to trapped undissociated water and carbonates.

\subsection{In Vitro Enamel Surface Remineralization by Biomimetic} CHA Nanocrystals. SEM analysis allows investigating the morphology of both demineralized enamel and the fea-

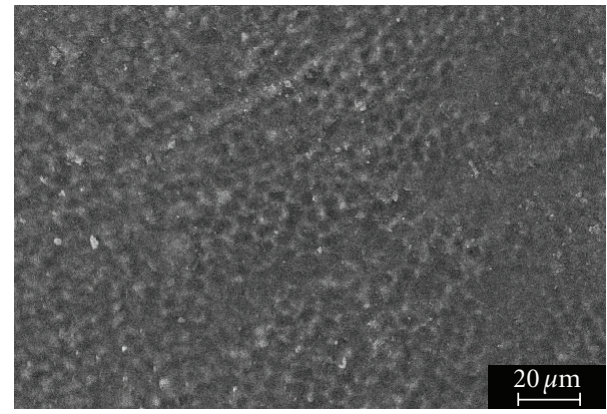

(a)

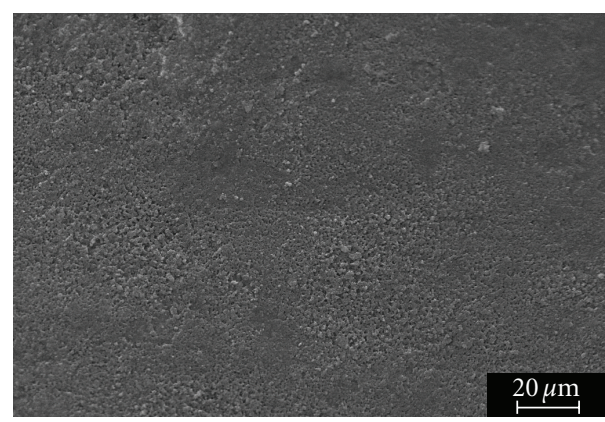

(b)

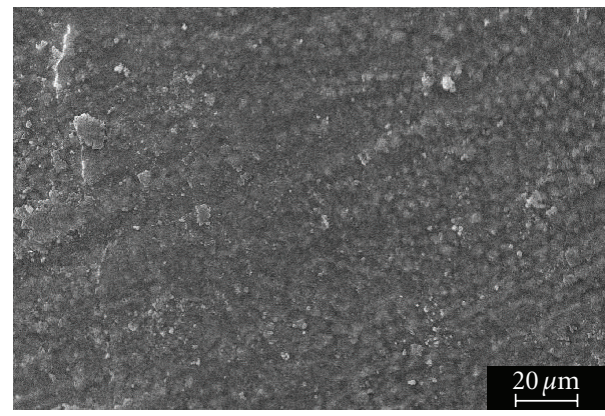

(c)

FIGURE 5: SEM image of enamel surface after application of $37 \%$ ortophosphoric acid for 1 minutes. The etching treatment removed aprismatic layer and exposed prismatic and interprismatic hydroxyapatite structures (a), remineralized enamel surface after treatment by synthetic CHA micro-clusters constituted of nanocrystals $20 \mathrm{~nm}$ (b) and $100 \mathrm{~nm}$ sized (c) and synthetic CHA micro-clusters.

tures observed after remineralization procedures induced by biomimetic CHA nanocrystals in vitro application.

The demineralization procedure by ortophosphoric acid $37 \%$ for 1 minute removes the aprismatic enamel, and exposed hydroxyapatite prisms became evident. Figure 5(a) shows demineralization of both interprismatic and prismatic enamel structures.

After treatment for 10 minutes by aqueous slurry of both synthetic $20 \mathrm{~nm}$ and $100 \mathrm{~nm}$ sized CHA nanocrystals, the surface of the demineralized enamel appears covered by the CHA phase (see Figures 5(b) and 5(c), resp.) arranged in a thick and homogeneous apatitic layer.

XPS analysis of spectral features of the $\mathrm{O} 1 \mathrm{~s}$ region of the enamel demineralized by ortophosphoric acid 37\% 
TABLE 1: XPS analysis of CHA nanocrystals, enamel tooth treated with ortophosphoric acid before and after treatment with either CHA 20 or $100 \mathrm{~nm}$ sized nanocrystals and after brushing with toothpaste containing booth CHA or fluoride.

\begin{tabular}{|c|c|c|c|c|c|c|c|c|c|}
\hline Sample & $\mathrm{O}(\%)$ & $\mathrm{C}(\%)$ & $\mathrm{Ca}(\%)$ & $\mathrm{P}(\%)$ & $\mathrm{N}(\%)$ & $\mathrm{Si}(\%)$ & $\mathrm{Na}(\%)$ & $\mathrm{F}(\%)$ & $\mathrm{Ca} / \mathrm{P}$ \\
\hline $20 \mathrm{~nm}$ CHA nanocrystals & 50.4 & 17.6 & 19.4 & 12.6 & - & - & - & - & 1.5 \\
\hline 100 nm CHA nanocrystals & 48.4 & 18.0 & 19.6 & 13.9 & - & - & - & - & 1.4 \\
\hline Tooth treated with ortophosphoric acid & 30.7 & 49.4 & 5.4 & 5.3 & 5.9 & 1.9 & 1.4 & - & 1.1 \\
\hline Tooth treated with $20 \mathrm{~nm}$ CHA nanocrystals & 43.3 & 27.3 & 13.4 & 10.1 & 2.3 & - & 1.9 & - & 1.3 \\
\hline Tooth treated with $100 \mathrm{~nm}$ CHA nanocrystals & 43.7 & 26.0 & 14.8 & 11.2 & 1.0 & - & 1.5 & - & 1.3 \\
\hline CHA containing toothpaste & 30.7 & 51.9 & 5.5 & 4.7 & 1.6 & 5.6 & - & - & 1.2 \\
\hline Fluoride containing toothpaste & 20.9 & 63.3 & 4.1 & 1.2 & 2.0 & 4.9 & - & 3.6 & 3.4 \\
\hline
\end{tabular}

for 1 minute shows a single broad band, in which it is difficult to determine precisely and to quantify the binding energy (BE) and, therefore, the kind of the surface oxygen components (see Figure 4(a)). On the contrary, the enamel remineralized by synthetic $100 \mathrm{~nm}$ sized CHA nanocrystals for 10 minutes shows a definite $O$ 1s shape fitted by three components at different binding energy (see Figure 4(b)). These components correspond to the same three ones used to fit $\mathrm{O} 1 \mathrm{~s}$ shape recorded for synthetic $100 \mathrm{~nm}$ sized CHA nanocrystals (see Figure 4(c)), the first at lower BE very intense peak is attributed to oxygen in phosphate group, the second peak is due to $\mathrm{OH}$ of the carbonate-hydroxyapatite, and a final peak at high $\mathrm{BE}$, can be attributed to trapped undissociated water and carbonate groups. These results unequivocally confirm the presence of synthetic CHA at the surface of the treated enamel and the consequent validation of the enamel remineralization. The same finding is pointed out by the ATR spectrum of enamel treated for 10 minutes by synthetic $100 \mathrm{~nm}$ sized CHA nanocrystals, showing appreciable higher intensity of the characteristic absorption bands of carbonate ions (1420-1460 and $1680 \mathrm{~cm}^{-1}$ ) in respect of the same absorption bands present in the demineralized enamel ATR spectrum. No differences are appreciable in the phosphate ions bands (1000-1100 and 530-580 $\left.\mathrm{cm}^{-1}\right)$. ATR spectrum (data not shown) of remineralized enamel reveals that surface apatite is richer in carbonate than natural one, such as synthetic $100 \mathrm{~nm}$ sized CHA nanocrystals.

\subsection{In Vitro Enamel Surface Remineralization by Toothpaste} Containing either Fluoride or Biomimetic CHA Nanocrystals Microclusters. SEM analysis allowed us to investigate the morphology of both demineralized enamel and the features observed after a remineralization process which utilizes in vitro application of toothpaste containing either fluoride or CHA microclusters constituted of $100 \mathrm{~nm}$ in size nanocrystals.

The surfaces of the teeth treated with fluoride (see Figure 6(b)) were not consistently changed respect to that of demineralization by ortophosphoric acid (see Figure 6(c)) Actually both the interprismatic and prismatic enamel structures appear still evident. On the contrary after treatment of the enamel slabs with a toothpaste containing synthesized CHA microclusters constituted of $100 \mathrm{~nm}$ sized nanocrystals, the interprismatic and prismatic enamel structures appear to be completely hidden by a thick homogeneous apatitic layer (see Figure 6(a)).

The XRD patterns collected on the surface of enamel slabs after treatment with CHA or fluoride toothpaste and water are reported in Figures 7(b), 7(c), and 7(d), respectively, and compared with the XRD pattern (see Figure 7(a)) of CHA microclusters constituted of $100 \mathrm{~nm}$ sized nanocrystals utilized to prepare the used CHA toothpaste. The XRD diffraction maxima recorded on the surface of enamel slabs treated with fluoride containing toothpaste appear slightly more sharpened than those obtained on the enamel etched slabs brushed only with water. This observation reveals an increased crystallinity degree probably due to a partial structural conversion of hydroxyapatite into fluoride substituted hydroxyapatite. On the contrary, the XRD pattern obtained on the surface of enamel slabs brushed with CHA containing toothpaste shows the broadened diffraction maxima characteristic of the synthetic biomimetic CHA, revealing its presence on the enamel surface. The CHA not removed by brushing procedures suggests the formation of chemical bonds between the synthetic CHA microclusters constituted of $100 \mathrm{~nm}$ sized nanocrystals and natural enamel apatite crystals. These bonds allow the formation of a persistent CHA coating on the enamel surface whose morphology was detected by SEM analysis.

The surface $\mathrm{Ca} / \mathrm{P}$ molar ratio determined by XPS analysis for demineralized enamel slabs before and after in vitro remineralization by brushing whit toothpaste containing either fluoride or CHA are compared in Table 1. In this table, a comparison with the $\mathrm{Ca} / \mathrm{P}$ molar ratio of $\mathrm{CHA}$ microclusters constituted of $100 \mathrm{~nm}$ sized nanocrystals also present. The enamel surface $\mathrm{Ca} / \mathrm{P}$ molar ratio changes before and after the brushing treatment with toothpaste containing fluoride, assuming a value of 3.4 very different from the apatite stoichiometric one $(\mathrm{Ca} / \mathrm{P}=1.7)$. This finding reveals that the only structural modification of enamel hydroxyapatite induced by fluoride is restricted to a partial hydroxyl groups replacement by fluoride ions without affecting appreciably the $\mathrm{Ca}$ and phosphate structural network. On the contrary, enamel slabs treated with the toothpaste containing synthesised CHA microclusters of $100 \mathrm{~nm}$ sized nanocrystals exhibit a surface $\mathrm{Ca} / \mathrm{P}$ molar ratio very similar to that one of the synthetic CHA.

This coating is highly less crystalline than native enamel apatite, and consists of a new apatitic mineral deposition 


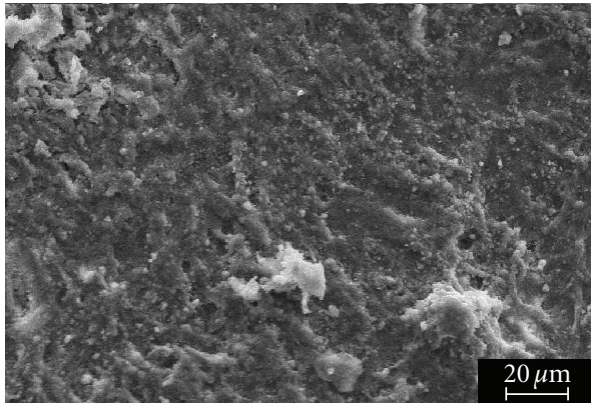

(a)

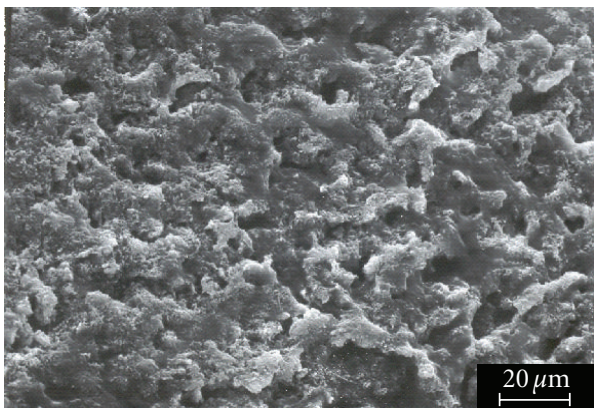

(b)

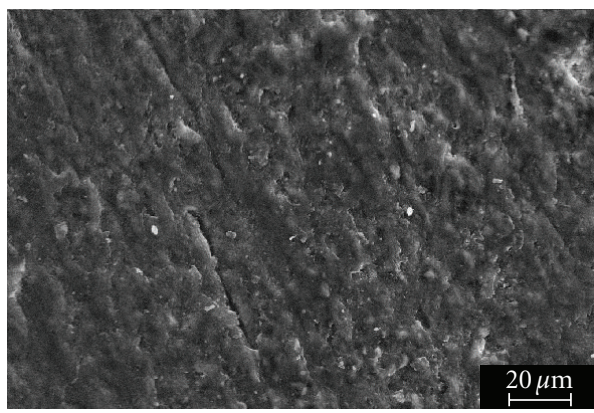

(c)

FIGURE 6: SEM images of enamel after brushing treatment with (a) CHA toothpaste containing, (b) fluoride containing toothpaste, and (c) ortophosphoric acid application.

which progressively fills the scratches and pits. On the contrary, the surface remineralization observed on the specimens treated with fluoride containing toothpaste is mainly based on chemical-physical enamel apatite surface modifications rather than a formation of a new mineral deposition.

The CHA biomimetic coating formation is a remineralization process corresponding to a new apatite deposition in the demineralized area of enamel surface.

\section{Discussion}

Enamel is the hardest and most mineralized tissue of human body. It is structured in order to resist to mechanical injuries, abrasion, and chemical attack. Differently from all the other mineralized tissues, it lacks proteins even if they are essential to its formation. Actually, matrix proteins are

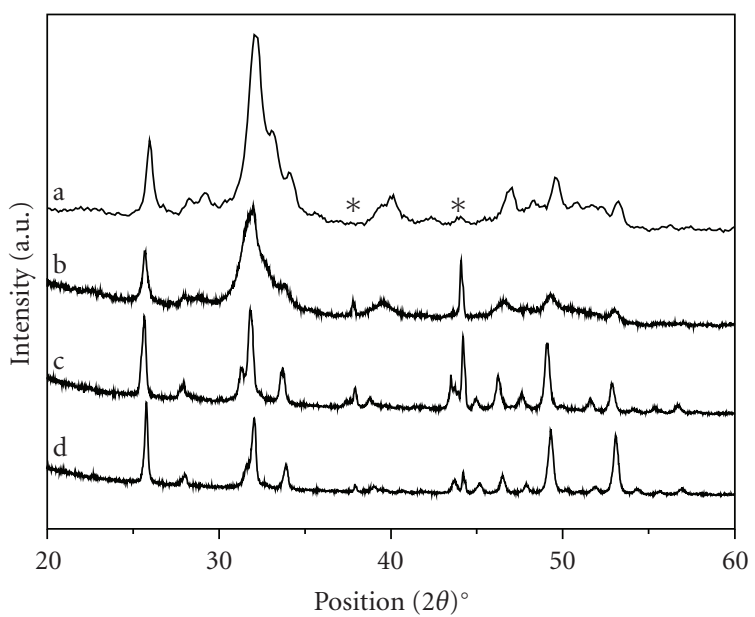

FIgURE 7: (a) XRD pattern of synthetic CHA, (b) enamel after brushing treatment with CHA containing toothpaste, (c) enamel after brushing treatment with fluoride containing toothpaste, (d) enamel after brushing treatment with water. ${ }^{*}$ indicates $\mathrm{Al}$ holder diffraction maxima.

cleaved by proteinases secreted by the ameloblasts during tooth formation; hence, the matrix proteins of enamel are not incorporated into enamel prisms [38]. Degradation and resumption of enamel matrix proteins is the reason why enamel prisms, once formed, cannot be remodelled. After enamel prism formation, only the amount of hydroxyapatite within the prisms may decrease in consequence of chemical changes into the oral environment.

Acid attack is one of the major causes of enamel hydroxyapatite loss. It may occur even in young age as a consequence of plaque metabolism or simply due to food and beverage intakes [2-4].

In the present paper, synthetic carbonate-hydroxyapatite biomimetic nanocrystals have been chemical-physical characterized and investigated regarding the possibility to obtain an in vitro remineralization of the altered enamel surfaces.

The experimental model used in the present investigation was the demineralization by means of ortophosphoric acid of sound enamel of the interproximal surfaces and its subsequent remineralization.

This model was chosen because the demineralizing effect of ortophosphoric acid is well known in terms of chemical and microhistological features because it is an essential part of the procedures of adhesive restoration applications.

The SEM observations showed that the enamel is characterized by both amorphous and prismatic hydroxyapatite and by an irregular surface even. The use of ortophosphoric acid causes an exposure of prism and a loss of both interprismatic and prismatic substances.

The treatment of demineralized enamel only for ten minutes, by synthetic CHA nanocrystals, induces a consistent enamel remineralization through the formation of a surface carbonate-hydroxyapatite coating. This coating is due to the chemical bond of the synthetic CHA nanocrystals biomimetic for composition, structure, size, and morphology on the surface prismatic hydroxyapatite enamel. It can 
be supposed that the application of CHA nanocrystals $20 \mathrm{~nm}$ sized allows a better mineralization in the lower surface fissure, because the interprismatic and prismatic enamel structures appear totally hidden. Using an equal time of treatment, the application of CHA nanocrystals $100 \mathrm{~nm}$ sized produces the formation of a homogeneous coating which hides interprismatic and prismatic enamel structures when examined with SEM.

In this paper, an in vitro enamel surface remineralization by brushing with toothpaste containing either fluoride or biomimetic CHA nanocrystals microclusters has been also carried out. The XRD patterns, SEM images, and XPS spectra collected on the surface of enamel slabs before and after treatment with CHA or fluoride toothpaste underline the possibility to obtain an enamel remineralization through the formation of a surface apatite coating which covers the enamel structure avoiding the most probably health dangerous fluoride effects, to contrast the mechanical abrasion and acid attacks to which tooth enamel is exposed. The documented CHA biomimetic coating formation which is less crystalline than enamel natural apatite represents an enamel repair process corresponding to an apatite deposition inside the demineralized area of enamel surface and may be considered an innovative approach to contrast enamel demineralization.

\section{Acknowledgments}

The authors acknowledge financial support from the University of Bologna, C.I.R.C.M.S.B., the Italian Ministero dell'Istruzione, Università e Ricerca (MIUR) PRIN Project no. 2006-032335, and the COSWELL President Paolo Gualandi for his cheering eagerness in suggesting this research work.

\section{References}

[1] J. D. Eccles, "Dental erosion of nonindustrial origin. A clinical survey and classification," The Journal of Prosthetic Dentistry, vol. 42, no. 6, pp. 649-653, 1979.

[2] C. Deery, M. L. Wagner, C. Longbottom, R. Simon, and Z. J. Nugent, "The prevalence of dental erosion in a United States and a United Kingdom sample of adolescents," Pediatric Dentistry, vol. 22, no. 6, pp. 505-510, 2000.

[3] C. R. Dugmore and W. P. Rock, "The prevalence of tooth erosion in 12-year-old children," British Dental Journal, vol. 196, no. 5, pp. 279-282, 2004.

[4] Y. H. Al-Dlaigan, L. Shaw, and A. Smith, "Dental erosion in a group of British 14-year-old, school children-part I: prevalence and influence of differing socioeconomic backgrounds," British Dental Journal, vol. 190, no. 3, pp. 145-149, 2001.

[5] I. B. Arnadóttir, S. R. Sæmundsson, and W. P. Holbrook, "Dental erosion in Icelandic teenagers in relation to dietary and lifestyle factors," Acta Odontologica Scandinavica, vol. 61, no. 1, pp. 25-28, 2003.

[6] J. H. Nunn, P. H. Gordon, A. J. Morris, C. M. Pine, and A. Walker, "Dental erosion-changing prevalence? A review of British national childrens' surveys," International Journal of Paediatric Dentistry, vol. 13, no. 2, pp. 98-105, 2003.
[7] British Soft Drinks Association, "A shared responsibility," Annual Report, The British Soft Drinks Association, London, UK, 2002-2003.

[8] C. C. Costa, I. C. S. Almeida, and L. C. Costa Filho, "Erosive effect of an antihistamine-containing syrup on primary enamel and its reduction by fluoride dentifrice," International Journal of Paediatric Dentistry, vol. 16, no. 3, pp. 174-180, 2006.

[9] M. Kitchens and B. M. Owens, "Effect of carbonated beverages, coffee, sports and high energy drinks, and bottled water on the in vitro erosion characteristics of dental enamel," Journal of Clinical Pediatric Dentistry, vol. 31, no. 3, pp. 153159, 2007.

[10] A. Wiegand and T. Attin, "Occupational dental erosion from exposure to acids-a review," Occupational Medicine, vol. 57, no. 3, pp. 169-176, 2007.

[11] A. Lussi, T. Jaeggi, and D. Zero, "The role of diet in the aetiology of dental erosion," Caries Research, vol. 38, supplement 1, pp. 34-44, 2004.

[12] A. Lussi, E. Hellwig, D. Zero, and T. Jaeggi, "Erosive tooth wear: diagnosis, risk factors and prevention," American Journal of Dentistry, vol. 19, no. 6, pp. 319-325, 2006.

[13] N. X. West, A. Maxwell, J. A. Hughes, D. M. Parker, R. G. Newcombe, and M. Addy, "A method to measure clinical erosion: the effect of orange juice consumption on erosion of enamel," Journal of Dentistry, vol. 26, no. 4, pp. 329-335, 1998.

[14] N. X. West, J. A. Hughes, D. M. Parker, R. G. Newcombe, and M. Addy, "Development and evaluation of a low erosive blackcurrant juice drink 2. Comparison with a conventional blackcurrant juice drink and orange juice," Journal of Dentistry, vol. 27, no. 5, pp. 341-344, 1999.

[15] J. A. Hughes, N. X. West, D. M. Parker, R. G. Newcombe, and M. Addy, "Development and evaluation of a low erosive blackcurrant juice drink in vitro and in situ 1. Comparison with orange juice," Journal of Dentistry, vol. 27, no. 4, pp. 285289, 1999.

[16] J. A. Hughes, N. X. West, D. M. Parker, R. G. Newcombe, and M. Addy, "Development and evaluation of a low erosive blackcurrant juice drink 3. Final drink and concentrate, formulae comparisons in situ and overview of the concept," Journal of Dentistry, vol. 27, no. 5, pp. 345-350, 1999.

[17] A. V. Nieuw Amerongen, C. H. Oderkerk, and A. A. Driessen, "Role of mucins from human whole saliva in the protection of tooth enamel against demineralization in vitro," Caries Research, vol. 21, no. 4, pp. 297-309, 1987.

[18] B. T. Amaechi, S. M. Higham, W. M. Edgar, and A. Milosevic, "Thickness of acquired salivary pellicle as a determinant of the sites of dental erosion," Journal of Dental Research, vol. 78, no. 12, pp. 1821-1828, 1999.

[19] Y. Nekrashevych and L. Stösser, "Protective influence of experimentally formed salivary pellicle on enamel erosion: an in vitro study," Caries Research, vol. 37, no. 3, pp. 225-231, 2003.

[20] D. T. Zero and A. Lussi, "Erosion-chemical and biological factors of importance to the dental practitioner," International Dental Journal, vol. 55, no. 4, supplement 1, pp. 285-290, 2005.

[21] J. D. B. Featherstone, R. Glena, M. Shariati, and C. P. Shields, "Dependence of in vitro demineralization of apatite and remineralization of dental enamel on fluoride concentration," Journal of Dental Research, vol. 69, pp. 620-625, 1990.

[22] European Food Safety Authority, "Opinion of the scientific panel on dietetic products, nutrition and allergies on a request 
from the Commission related to the tolerable upper intake level of fluoride," The EFSA Journal, vol. 192, pp. 1-65, 2005.

[23] D. G. Pendrys and J. W. Stamm, "Relationship of total fluoride intake to beneficial effects and enamel fluorosis," Journal of Dental Research, vol. 69, pp. 529-538, 1990.

[24] G. M. Whitford, "The physiological and toxicological characteristics of fluoride," Journal of Dental Research, vol. 69, pp. 539-549, 1990.

[25] C. Ganss, J. Klimek, U. Schäffer, and T. Spall, "Effectiveness of two fluoridation measures on erosion progression in human enamel and dentine in vitro," Caries Research, vol. 35, no. 5, pp. 325-330, 2001.

[26] C. Ganss, J. Klimek, V. Brune, and A. Schürmann, "Effects of two fluoridation measures on erosion progression in human enamel and dentine in situ," Caries Research, vol. 38, no. 6, pp. 561-566, 2004.

[27] A. Wiegand and T. Attin, "Influence of fluoride on the prevention of erosive lesions-a review," Oral Health \& Preventive Dentistry, vol. 1, no. 4, pp. 245-253, 2003.

[28] A. Young, P. S. Thrane, E. Saxegaard, G. Jonski, and G. Rölla, "Effect of stannous fluoride toothpaste on erosion-like lesions: an in vivo study," European Journal of Oral Sciences, vol. 114, no. 3, pp. 180-183, 2006.

[29] M. F. Teaford, "A review of dental microwear and diet in modern mammals," Scanning Microscopy, vol. 2, no. 2, pp. 1149-1166, 1988.

[30] N. Roveri and B. Palazzo, "Hydroxyapatite nanocrystals as bone tissue substitute," in Tissue, Cell and Organ Engineering, C. S. S. R. Kumar, Ed., vol. 9 of Nanotechnologies for the Life Sciences, pp. 283-307, Wiley-VCH, Weinheim, Germany, 2006.

[31] B. Palazzo, M. Iafisco, M. Laforgia, et al., "Biomimetic hydroxyapatite-drug nanocrystals as potential bone substitutes with antitumor drug delivery properties," Advanced Functional Materials, vol. 17, no. 13, pp. 2180-2188, 2007.

[32] E. Landi, A. Tampieri, G. Celotti, and S. Sprio, "Densification behaviour and mechanisms of synthetic hydroxyapatites," Journal of the European Ceramic Society, vol. 20, no. 14-15, pp. 2377-2387, 2000.

[33] S. P. A. Coswell, G. Gazzaniga, N. Roveri, et al., "Biologically active nanoparticles of a carbonate-substituted hydroxyapatite, process for their preparation and compositions incorporating the same," EU patent no. 005146, 2006.

[34] S.-C. Liou, S.-Y. Chen, H.-Y. Lee, and J.-S. Bow, "Structural characterization of nano-sized calcium deficient apatite powders," Biomaterials, vol. 25, no. 2, pp. 189-196, 2004.

[35] Z. E. Erkmen, "The effect of heat treatment on the morphology of D-Gun sprayed hydroxyapatite coatings," Journal of Biomedical Materials Research Part B, vol. 48, no. 6, pp. 861868, 1999.

[36] S. Brunauer, P. H. Emmett, and E. Teller, "Adsorption of gases in multimolecular layers," Journal of the American Chemical Society, vol. 60, no. 2, pp. 309-319, 1938.

[37] K. P. Quinlan and M. A. DeSesa, "Spectrophotometric determination of phosphorus as melybdovanadophosporic acid," Analytical Chemistry, vol. 27, no. 10, pp. 1626-1629, 1955.

[38] J. P. Simmer and A. G. Fincham, "Molecular mechanisms of dental enamel formation," Critical Reviews in Oral Biology and Medicine, vol. 6, no. 2, pp. 84-108, 1995. 

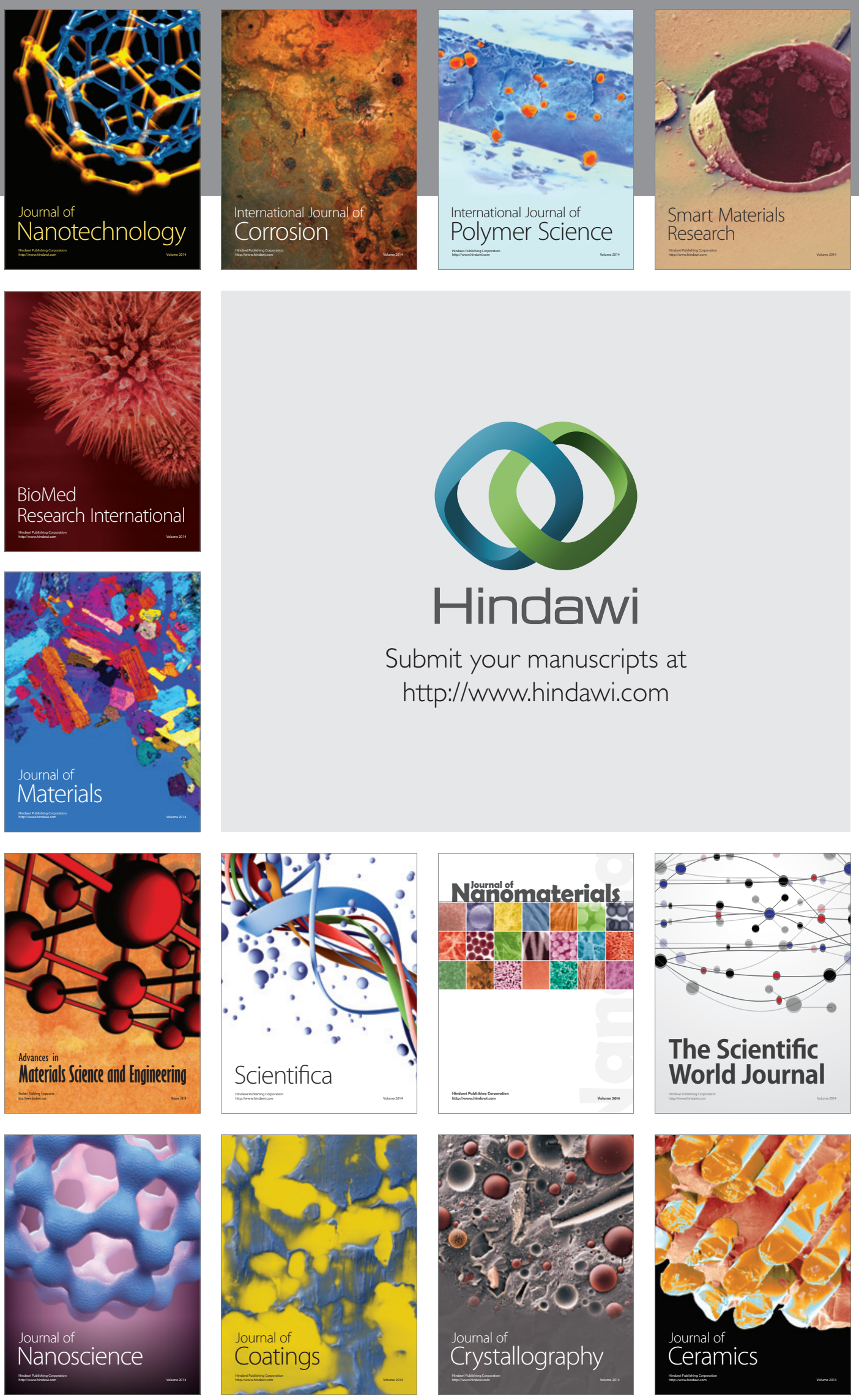

The Scientific World Journal

Submit your manuscripts at

http://www.hindawi.com

\section{World Journal}

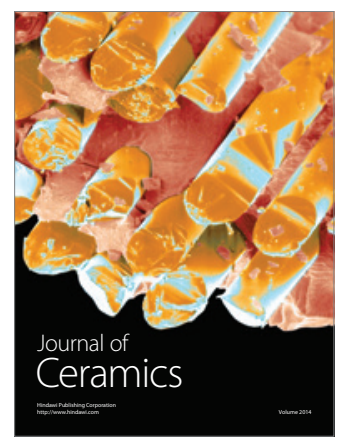

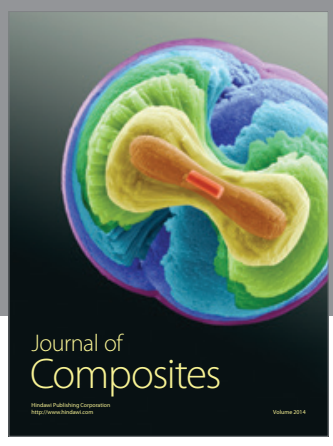
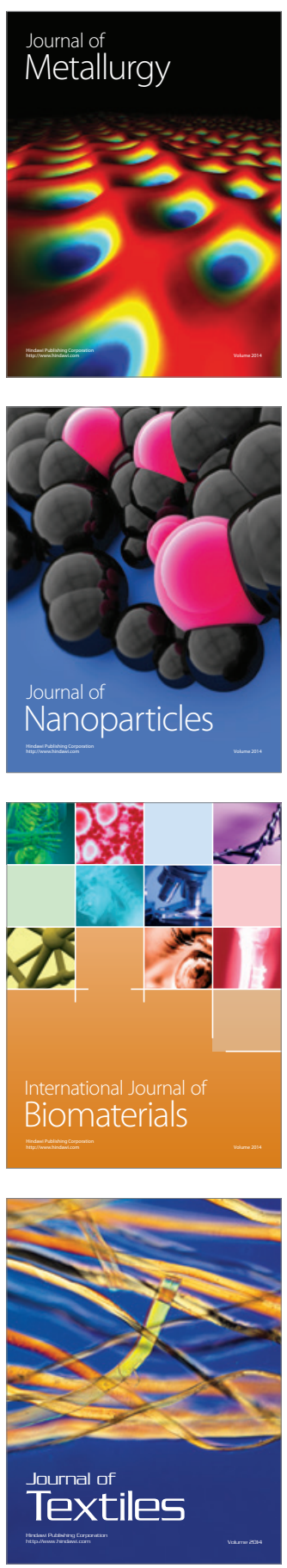